\title{
BRITISH JOURNAL OF PAIN
}

\section{TITLE PAGE}

Title: Lived experiences of informal caregivers of people with chronic musculoskeletal pain: a systematic review and meta-ethnography.

Concise Title: MSK pain caregiver's lived experiences

Authors: Smith TO,,$^{1,2}$ Fletcher J, ${ }^{1,3}$ Lister $\mathrm{S}^{4}$

\section{AFFILIATIONS:}

1. Nuffield Department of Orthopaedics, Rheumatology and Musculoskeletal Sciences, University of Oxford, Oxford, UK

2. Faculty of Medicine and Health Sciences, University of East Anglia, Norwich, UK

3. Physiotherapy Department, Connect Health, Milton Keynes, UK

4. Physiotherapy Department, Norfolk and Norwich University Hospital NHS Foundation Trust, Norwich, UK

Corresponding Author: Dr Toby Smith, Nuffield Department of Orthopaedics, Rheumatology and Musculoskeletal Sciences, Botnar Research Centre, University of Oxford, Old Road, Oxford, OX3 7LD, UK. Email: toby.smith@ndorms.ox.ac.uk; Telephone: 01865227663

Twitter handle: @tobyosmith 


\section{ABSTRACT}

BACKGROUND: People with chronic pain often seek support from friends and family for everyday tasks. These individuals are termed informal caregivers. There remains uncertainty regarding the lived experiences of these people who care for individuals with chronic musculoskeletal pain. The aim of this paper is to synthase the evidence on the lived experiences of informal caregivers providing care to people with chronic musculoskeletal pain.

METHODS: A systematic literature review was undertaken of published and unpublished literature databases including: EMBASE, MEDLINE, CINAHL, PubMed, the WHO International Clinical Trial Registry and ClinicalTrials.gov registry (to September 2019). Qualitative studies exploring the lived experiences of informal caregivers of people with chronic musculoskeletal pain were included. Data were synthesised using a meta-ethnography approach. Evidence was evaluated using the Critical Appraisal Skills Programme (CASP) qualitative appraisal tool.

RESULTS: From 534 citations, 10 studies were eligible (360 participants: 171 informal caregivers of 189 care recipients). The evidence was moderate quality. Seven themes arose: the relationship of caregivers to healthcare professionals, role reversal with care recipients; acting the confidant to the care recipient; a constant burden in caregiving; legitimising care recipient's condition; knowledge and skills to provide caregiving; and the perception of other family members and wider-society to the caregiver/care recipient dyad.

CONCLUSIONS: The lived experiences of caregivers of people with chronic musculoskeletal pain is complex and dynamic. There is an inter-connected relationship between caregivers, care recipients and healthcare professionals. Exploring how these experiences can be modified to improve a caregiving dyad's lived experience is now warranted.

Keywords: Caring; chronic pain; support; dyad; qualitative 


\section{INTRODUCTION}

Chronic musculoskeletal pain is a complex, disabling condition. It is globally prevalent across the lifespan. ${ }^{1,2}$ People with chronic musculoskeletal pain frequently receive informal support from family members and friends, to assist in everyday tasks. Such assistance can range from help with personal activities of daily living such as washing, dressing and toileting, assistance preparing meals, shopping or housework, to managing money and household administration tasks. ${ }^{3,4}$ These unpaid 'helping' individuals are known as informal caregivers. Caring for individuals with chronic musculoskeletal pain can be a physical and emotional burden. ${ }^{5}$ Both people with pain (care recipients) and their caregivers demonstrate significant pain related to elevated levels of psychological distress. ${ }^{6,7}$

The lived experience of caregiving for people who have non-musculoskeletal pain conditions has been previously reported, most notably in dementia, ${ }^{8,9}$ cancer $^{8,10}$ and mental illness. ${ }^{11}$ These have highlighted various lived experiences, each of which offer difference experiences dependent on the disease state of individuals. Whilst these are recurrent themes such as constant burden, , ,10 knowledge $^{9,11}$ and role reversal, ${ }^{11}$ there are also differences related to reward, worth and pleasure which have been associated with caregiving for people with terminal illness, ${ }^{12,13}$ but also fear and concern regarding harm, associated with caregiving for people with cognitive impairment. ${ }^{14,15}$

Various sociological models have been developed to explain caregiver-care recipient dyads. These include the Social Ecological Theory ${ }^{16}$ where caregiving is influenced by various social contexts, the Life Course Theory ${ }^{17}$ where caregiving has discrete entry, exit and transition points dependent on time. The Pearlin Stress Process Model ${ }^{18}$ also helps descript how caregivers experience, appraise and cope with care demands, with moderators to this, to establish a positive or negative caregiving experience.

Bowlby's ${ }^{19}$ Attachment Theory has been frequently adopted to explain caregiving experiences. This suggests that humans have evolved to ensure proximity to caregivers during times of threat throughout the life-span. ${ }^{20}$ This is supported specifically to pain, through the communal coping model of pain catastrophizing. ${ }^{21}$ In this, distress is communicated to significant others as a means of seeking social support. ${ }^{22}$ Consequently, through prolonged interactions, people develop enduring cognitive schemas (attachment orientations) which guide future behaviours and expectations. ${ }^{23,24}$ Where there is inconsistency or unresponsiveness of caregiving between the dyad, a state of 'insecure attachment' may occur ${ }^{25}$ This state has major negative physical and psychological consequences, ${ }^{26,27}$ particularly around pain catastrophising and perceived pain severity. ${ }^{28}$ It can also have a negative effect on 
relationship satisfaction within the caregiving dyad. ${ }^{29,30}$ However, such concepts can not be attributed to all, given the heterogeneity in individual's perceptions, their society and time-course of disease process. The multifactorial nature of pain which constantly evolves, means understanding this phenomena is challenging. These are then influence by wider, cultural understanding not only to disease, but also social expectancies and responsibilities to offer formal and informal care. These have not been previously explored within the musculoskeletal literature.

Previous systematic reviews have focused on the lived experiences of people with chronic musculoskeletal pain, not their caregivers. ${ }^{31-33}$ We aimed to address this. This paper therefore synthesises the best available evidence exploring the experiences of informal caregivers of people with chronic musculoskeletal pain.

\section{MATERIALS AND METHODS}

This systematic review was registered through the International Prospective Register of Systematic Reviews database (PROSPERO Registration: CRD42019136168). It was reported following the Preferred Reporting Items for Systematic review and Meta-Analysis (PRISMA) guidelines ${ }^{34}$ and the eMERGe reporting guidance. ${ }^{35}$

\section{Search Strategy}

The search was undertaken by one reviewer (TS) using published and unpublished literature databases including EMBASE, MEDLINE, CINAHL, PubMed the WHO International Clinical Trial Registry and ClinicalTrials.gov registry. The search strategy for EMBASE is presented in Supplementary Table 1. This was modified for each database. Searches were performed from database inception to $1^{\text {st }}$ September 2019. To augment the principal search strategy, a forward citation search was performed for all included studies using the Scopus database. Secondly, a backwards citation search was conducted through a review of all included study reference lists. Additionally, all corresponding authors from included studies were contacted to assess the completeness of the search results. We placed no restriction on the date of publication, risk of bias or language of publication. 


\section{Selection Criteria}

Two reviewers (TS, SL) independently reviewed all titles and abstracts from the search results. Fulltext papers for all potentially eligible studies were independently reviewed by each reviewer (TS,SL) to determine final inclusion. Disagreements between the two reviewers were resolved through discussion.

Studies were included if they met the following:

- Qualitative research studies (e.g. ethnography, phenomenology) and/or data were collected using any of the known qualitative data collection methods (e.g. focus group interviews, individual interviews, observation, diaries, oral histories), and employed qualitative methods of data analysis (e.g. thematic analysis, framework approach, grounded theory, thematic network analysis). Mixed-method studies were also included if data could be derived to answer this research question.

- The population of studies were adults informal caregivers (18 years and older). Informal caregivers are defined as spouses, partners, significant others or family members/friends who supported adults with activities of daily living (ADLs) and instrumental ADLs (IADLs) and are not paid for providing this support. The informal caregivers provide care to individuals with chronic musculoskeletal pain. Chronic musculoskeletal pain was defined as any cause or disease causing pain, originating from the musculoskeletal system (i.e. bone, joint, muscle, ligament, tendon or nerve). Chronic was defined as pain experienced for six weeks or longer. ${ }^{36}$

Studies were excluded if they included:

- Care recipients of people who have pain from a non-musculoskeletal origin including cancer, surgery or childbirth.

- Care recipients who have intellectual disabilities and/or cognitive impairment.

- Care recipients living in a hospital, hospice, institutional care, nursing or residential home.

- Information solely gathered from a care recipient rather than caregiver. 


\section{Data Extraction}

Data were extracted onto a pre-defined data extraction form by one reviewer (TS) and verified by a second (SL). Disagreements in data extraction between the reviewers, particularly on intervention content and study results, were resolved through discussion. Where the same study was reported across two or more papers, these were classified as a single study to avoid multiple participant counting.

Data extracted included: country of origin, year of study conduct, number and characteristics of participants including data on: age and gender (care recipient and caregiver), musculoskeletal disease diagnosis and severity, and medical morbidities. First- and second-order data were extracted which explored: perceptions, attitudes, experiences and views of people on being an informal caregiver for someone with chronic musculoskeletal pain.

\section{Data Synthesis}

The qualitative study data were synthesised using a meta-ethnography approach. ${ }^{37}$ This approach uses first, second and third-order analysis of constructs. The first-order constructs are primary themes reflecting participants' understandings extracted from the 'results' sections of included studies. The second-order constructs are the interpretations of participants' understandings made by authors of included studies, extracted from the 'discussion' sections of included studies. Finally, third-order constructs were generated by two reviewers (TS, JF) through discussion and interpretation of the firstand second-order construct. This is explained below.

First-order themes were grouped into categories independently by two reviewers (TS, JF). Categories were created on the basis of primary data from the included studies rather than based on wider literature or previous scoping searches. ${ }^{38}$ These were tabulated and used to develop a conceptual map. The findings of this were discussed amongst the review team. This was repeated for all secondorder constructs. We labelled where the first- and second-order constructs derived for each code to explore how the papers and constructs related to one-another. Such constant comparative techniques were used to compare how emergent categories related to the primary data/original texts in their similarities (reciprocal analysis) and in their contradictions (refutational analysis). 
We translated second-order to third-order constructs which emerged in interpretive analysis, checking translations in iterative cyclical processes. ${ }^{39}$ The analysis of these findings were collapsed into interpretive themes to develop a line of argument. ${ }^{37,38}$

\section{Quality Assessment}

Two reviewers (TS, SL) independently critically appraised each included study using the Critical Appraisal Skills Programme (CASP) qualitative appraisal tool..$^{40}$ This tool was deemed as appropriate as, in the review team's opinion, it included all key components considered as important in qualitative research on this research question. Disagreements in scoring between the reviewers were resolved through discussion.

\section{RESULTS}

The search results are summarised in Figure 1. In total, 534 individual titles and abstracts were reviewed following de-duplication. From these, 10 studies were eligible and included.

\section{Characteristics of Included Studies}

The characteristics of the included studies are summarised in Table 1. In total, 360 participants were included; 171 informal caregivers of 189 care recipients. Mean age for caregivers ranged from 37 years ${ }^{41}$ to 55 years. ${ }^{42}$ Mean age of care recipients ranged from 41 years ${ }^{43}$ to 74 years. ${ }^{44}$ Five studies were undertaken in the UK. ${ }^{43.45-48}$ Single studies originated from Taiwan, ${ }^{44}$ a combined UK-Dutch cohort, ${ }^{41}$ Australia, ${ }^{49}$ Sweden ${ }^{42}$ and Canada. ${ }^{50}$ All studies collected interview data through face-to-face interviews.

The relationship of caregiver to care recipient was reported in all but one study. ${ }^{40}$ The principal caregiver was most frequently a spouse or partner. ${ }^{42,43,45-48,50}$ West et al ${ }^{49}$ interviewed partners or family members, whilst Richardson et $\mathrm{al}^{45}$ and McCluskey et $\mathrm{al}^{43,46}$ also interviewed children. Half of all caregivers in $\mathrm{Hsu}$ et al ${ }^{44}$ study were sons with $25 \%$ being daughter-in-laws.

The musculoskeletal pathology of the care recipient was reported in all studies. Care recipients presented with low back pain or general musculoskeletal pain causing work absenteeism in three 
studies, ${ }^{41,43,46}$ fibromyalgia in three studies, ${ }^{42,45,50}$ chronic pain or chronic widespread pain in two studies, ${ }^{48,49}$ with single studies recruiting caregivers of care recipients with knee osteoarthritis ${ }^{44}$ or neuropathic pain. ${ }^{47}$

\section{Quality Assessment}

The CASP Qualitative Tool results are summarised in Table 2. Included studies were moderate quality evidence. This was awarded as whilst all studies demonstrated appropriate research rigor in design, recruitment, data collection and analysis approaches adopted (Table 2). no study clearly explored the relationship between the researcher and participants. Whilst four studies wither conducted interviews with caregivers and care recipients together, ${ }^{47}$ or did not state if this occurred. ${ }^{42,44,45}$ Given the importance of defining the role between researcher and participant, and potential impact this may have on social desirability bias and openness to share lived experiences, the classification of 'moderate quality evidence' was deemed appropriate by the review team.

\section{Meta-synthesis}

All 10 studies were included in the meta-ethnography. A summary of the first, second and third order constructs which formed the basis of the meta-ethnography are presented in Table 3. Seven themes identified aspects of the lived experiences of caregivers of people with chronic musculoskeletal pain: caregiving dyad-healthcare professional relationship; role reversal; the confidant; constant burden of caregiving; legitimising the condition; knowledge and skills; family and societal perceptions.

\section{Caregiver-Health Professional Relationships}

A consistent finding across the evidence was that informal caregivers perceived themselves in a supplementary role to healthcare professionals for symptom management. ${ }^{42-46,48,50}$ Richardson et al ${ }^{45}$ respondent's emphasised caregiving as secondary in importance to that of healthcare professionals, where caregivers were "helping hands". ${ }^{43,45}$ However Hsu et al ${ }^{44}$ contrasts this, emphasising physical assistance was a key component to the lived experiences of valuable caregiving. It is important to note that $\mathrm{Hsu}$ et $\mathrm{al}^{44}$ was the sole study to sample older care recipients with musculoskeletal pain (mean age 74 years). 
The literature emphases the emotional support which caregivers provide as a key 'alley' rather than 'central' player by caregivers who still perceived the health professionals in an authoritarian hierarchy. The disconnect to healthcare professional's acknowledgement of the caregiver role was negatively viewed by caregivers. ${ }^{42,48}$ However attitudes to the caregiving role are dynamic over time. Two studies highlighted that the earlier lived experience of the dyad saw caregivers as a key link to healthcare professionals, encouraging care recipients to seek medical attention. 42,44

\section{Role Reversal}

Role reversal occurred where informal caregivers take roles previously held by care recipients, such as domestic chores. ${ }^{42,45}$ However this was also in 'out-of-home' roles. Söderberg et al ${ }^{42}$ reported caregivers increasing or re-starting paid work due to financial pressures as care recipients become unable to work. This role reversal was universally perceived as a negative change.

Role reversal was highly cited as a source of caregiving dyad conflict. Whilst Söderberg et al ${ }^{42}$ reported that caregivers felt role reversal was a necessary part of caring, care recipients perceived this change negatively particularly when they felt usurped. ${ }^{41,45}$ Role reversal was more positively viewed when the caregiving dyad could share care tasks. ${ }^{45}$ This maintenance of identity, albeit through a limited role, was a positive step for caregiver and care recipients compared to the dyad sensing a complete loss of historical roles or identity.

\section{The Confidant}

Caregivers frequently perceived themselves as 'the confidant' to care recipients. There are repeated examples where care recipients only freely discuss pain symptoms to informal caregivers, closing discussion to other family members, friends and healthcare professionals. ${ }^{44,45}$ This "information control" was frequently expressed to create an impression of normality. ${ }^{45}$ Through this, Hsu et al ${ }^{44}$ argued that caregivers may be perceived as gatekeepers to pain discussion.

Both from UK populations, Newton-John et $\mathrm{al}^{48}$ and McCluskey et $\mathrm{al}^{41}$ identified additional roles which the 'confidant' played within the caregiving dyad. Newton-John et al ${ }^{48}$ suggests the confidant also have a "shielding" role, deflecting stress and care recipient rumination on negative thoughts and pain behaviours. The inherent trust between caregiver and care recipients mean coping strategies to 
control the discourse are made for the perceived best interests of the care recipient. Linked to this, McCluskey et al ${ }^{41}$ emphasised that active listening skills which caregivers have and their position as the confidant, can facilitate communication. This can aid coping but also help navigate social circumstances, to protect care recipients when symptoms flare.

\section{Constant Burden of Caregiving}

A recurrent theme was the constant demands placed on informal caregivers. Caregivers perceive a constant pressure to meet the care needs of their care recipients. ${ }^{42,45,47}$ This burden is magnified through the unpredictable and fluctuating nature of pain. This was perceived as a burden, with caregivers unable to "get a moments respite" from their role. ${ }^{43,49}$ This perceived dependency was associated with feelings of self-blame, originating from a desire to 'escape' from the situation. ${ }^{49}$

\section{Legitimising the Condition}

A key theme raised, particularly from caregivers of care recipients with fibromyalgia, was their role in legitimising pain. As the confidant or advocate, this position often falls on the caregiver. Richardson et al's ${ }^{45}$ caregivers acknowledged the "invisibility of pain" and their unique position of everyday contact to become the "witness to pain". ${ }^{43}$ Whilst not explored in-depth by participants, there is a notion that caregivers act as guarantors to care recipients, not just to healthcare professionals, ${ }^{42}$ but also to society and those who may question the legitimacy of chronic musculoskeletal pain. ${ }^{43}$

\section{$\underline{\text { Knowledge and Skills }}$}

Knowledge was a perceived core factor to the lived experiences of a positive caregiving dyad. Three studies reported a poor perception to caregiving originating from limited preparation to caregiving and an ad-hoc approach to learning caregiving skills. ${ }^{42,44,50}$ Importantly both Söderberg et $\mathrm{al}^{42}$ and Sylvain et al's $s^{50}$ care recipients had fibromyalgia. Sylvain et al's $s^{50}$ caregivers felt that improved knowledge would regain control, a strongly held and desirable requirement.

\section{Family and Societal Perceptions}

Caregiving for people with chronic musculoskeletal pain can be both positive and negative experiences in relation to social perceptions. When caregivers perceived their roles as positive, they emphasised 
a "reciprocal supportive relationship" and "supportive partnership". ${ }^{41,45}$ This was most evident where caregivers were spouses.$^{45}$ Caregiving was considered a joint endeavour, where activities were shared and enjoyed together. ${ }^{41,45}$ When relationships were considered 'enduring' and when caregivers perceived a personal responsibility to undertake a caregiving role, family and personal relationships between caregivers and care recipients were strengthened. ${ }^{42,49,50}$ Söderberg et al ${ }^{42}$ also highlighted that caregiving could bring families closer, creating a "common purpose" of caring for a family member. This contrasts to other caregivers who felt a negative social perception. Social deprivation, a poorer emotional and sexual relationship, role reversal and overarching resentment to changing work patterns with increased financial hardship, all negatively affected outlook on their family and relationships. ${ }^{42,47-49}$ Uncertainty over the future, particularly with the fluctuating nature of symptoms, imparted marital strain, ${ }^{47}$ driving a negative perception to informal caregiving.

\section{Line of Argument}

The theoretical construct developed from the 'line of argument' illustrates a complex, interconnecting relationship between caregiver, care recipients and healthcare professionals. This is a dynamic relationship, shaping the lived experiences of the caregiving dyad. The factors of family and social perception, caregiver/healthcare professional relationship, changing roles, acting the confidant, knowledge to legitimise the condition and skills to manage the constant burden of caregiving act as modifiers to a positive or negative lived experience for these individuals.

\section{DISCUSSION}

This is the first meta-ethnography of the lived experiences of informal caregivers of people with chronic musculoskeletal pain. It reports a dynamic situation influenced by internal (within the dyad) and external factors which may change the lived experience in response to chronic musculoskeletal pain. Clinically, since these modifiers to the lived experience have been identified, providing caregivers with support and guidance on facilitating positive factors may help improve their lived experience.

Caregivers, in the majority of included studies, were spouses. Caregiving for spouses and non-spouses may offer different lived experience. Whereas spousal caregiving was reported as a potential opportunity to bring family members closer and seen as a marital responsibility, ${ }^{41,50}$ when nonspouses were caregivers, such perceptions were not reported. Only Hsu et al ${ }^{44}$ interviewed a substantial proportion non-spousal caregivers. The strength of the relationship and degree of 
compassion and partnership could be a key modifier to the impact of chronic pain on the dyad, irrespective of the relationship between the dyad. Further evidence is required to explore whether there are differences in pain response, coping and lifestyle adaptation when caregivers are not spouses but other people important to a care recipient, given the potential difference in positive to negative caregiver lived experience.

A key theme arising from caregivers of people with fibromyalgia was that of legitimising the disease. Fibromyalgia, due to uncertainty surrounding its pathophysiological and diagnostic criteria, is viewed with caution by some health professionals. ${ }^{51}$ It is regarded, by some, as a non-entity or attributed to other chronic pain conditions. ${ }^{52}$ Both care recipients and caregivers, frequently feared the burden of having to legitimise this condition to friends, family, employees and healthcare professionals. This was universally viewed as an important component towards a negative lived experience. ${ }^{41,45}$ This suggests some variability in the lived experiences for different caregivers of care recipients based on musculoskeletal pathology. This concept may be, in-part, explained by the Social Ecological Model, ${ }^{16}$ where social contexts, namely in the attitudes of employers, healthcare progressions other friends and family members and society at-large, influence the caregiving dyad's perceptions towards their health and wellbeing. Modifying the attributes offered by such social contexts and perceptions of these by the caregivers, may provide a greater acceptance of this disease process. Whilst education and knowledge may aid modifying this from a negative lived experience within the caregiving dyad, changing the perception of wider society may be more challenging.

There remains limited evidence on how to positively influence a caregiving dyad to improve pain management skills. Keefe et al ${ }^{53-55}$ tested a pain-coping skills training intervention for people with knee osteoarthritis and their spouses. This was an education and skills/knowledge programme rather than behaviour change intervention. Such an intervention could have positive benefits, as explained by Pearlin's Stress Process Model. ${ }^{18}$ Through this, pain-coping skills training may act as a mediator/moderator to stress, thereby improving outcomes. Given that key components to explain the positive dyad relationships are based on influencing potential operant conditioning contingencies, through cognitive-behavioural theory, ${ }^{52,56}$ such a modifier may be in the form of a behaviour change intervention.

Previous studies have explored the lived experiences of caregivers of people with other diseases, notably dementia, ${ }^{8,9}$ cancer ${ }^{8,10}$ and mental illness. ${ }^{11}$ Whilst there are overlapping themes, most notably regarding constant burden, ${ }^{8,10}$ knowledge ${ }^{9,11}$ and role reversal, ${ }^{11}$ themes reported in this study 
specific to musculoskeletal pain include legitimising symptoms and acting as a confidant. This may be explained by the temporal nature of these disease processes. For instance, the Life Course Model ${ }^{17}$ acknowledges that chronic disease such as musculoskeletal pain may not necessarily offer a clear 'exit point' for change, with a prolonged caregiving period. In contrast, care-recipients with terminal cancer may offer a shorter, more intense period of stress for the caregiver.

A major limitation of current evidence was that authors not clearly exploring the relationship between the researcher and participants and how interviews were conducted within the caregiving dyad. Whilst six studies explicitly stated that caregiver and care recipient interviews were undertaken separately, ${ }^{41-43,46,48-50}$ this was jointly conducted in one study, ${ }^{47}$ and was not stated in three studies. ${ }^{42,44,45}$ Similarly, given the influence of context, it would be important that the researchers conducting interviews were not associated or perceived to be associated with healthcare provision. This highlights the potential of social constructs influencing response, as explained by the Social Ecological Model. ${ }^{16}$ By not offering impartial or open environments to share perceptions and experiences, there is a risk that respondents were unable to openly discuss their attitudes. The power which either caregiver, care recipient or healthcare professional respondents may have within a dyad could be considerable. This should be considered both in the interpretation of this meta-ethnography, but also in the design and reporting of future qualitative caregiving dyad research.

This study presents two key limitations. Firstly, no studies reported longitudinal data. The evidence which forms second- and third-order constructs were cross-sectional. Further study is required to explore whether caregiving dyads change over time. Secondly, the evidence was derived from European, North American and Australasian cohorts. There remains uncertainty as to whether these findings are transferability to other populations such as those from southern European countries, Africa, Asia or South America. These populations may have different perspectives to pain and caregiving. ${ }^{57,58}$ The common Western expectancies of life and illness are frequently as an unpredictable consequence of a disease presenting. Whereas East Asian caregiving is perceived as an expected role at a time in an individual's life. ${ }^{59}$ However such differences were not detected amongst the studies from European, North American and Australasian cohorts, with limited information provided on the cultural backgrounds of these respondents. Such analyses would therefore be valuable to explore whether cultural differences are important in the chronic musculoskeletal pain caregiving dyad. 


\section{CONCLUSION}

The lived experiences of informal caregivers of people with chronic musculoskeletal pain is complex. Positive lived experiences may be fostered through improved knowledge on caregiving, greater appreciation of the caregiving role in society and particularly between healthcare professionals and learning how to adapt to a change in identity as a caregiver. Further understanding on what mechanism such guidance and support can be provided to caregivers to modify these factors towards a positive lived experience, is now warranted. 
DECLARATIONS AND ACKNOWLEDGEMENTS

Funding: No funding was received to support this study.

Conflict of Interest: All authors declare that they have no conflicts of interest in relation to this paper.

Ethical Approvals: None required for this systematic review.

FIGURE AND TABLE LEGENDS

Figure 1: PRISMA flow-chart illustrating the search strategy results

Table 1: A summary of the CASP critical appraisal results for the ten included studies in this systematic review.

Table 2: A summary of the characteristics of the ten included studies in this systematic review.

Table 3: Matrix of first-, second- and third-order constructs and their attribution to included study.

Supplementary Table 1: The MEDLINE search strategy adopted in this systematic review.

REFERENCE 
1. Picavet HSJ, Verschuren WMM, Groot L, Schaap L, van Oostrom SH. Pain over the adult life course: 15 year-pain trajectories - the Doetinchem Cohort Study. Eur J Pain 2019: In Press.

2. GBD 2016 Disease and Injury Incidence and Prevalence Collaborators. Global, regional, and national incidence, prevalence, and years lived with disability for 328 diseases and injuries for 195 countries, 1990-2016: a systematic analysis for the Global Burden of Disease Study 2016. Lancet 2017; 390: 1211-1259.

3. Wolff JL, Spillman BC, Freedman VA, Kasper JD. A national profile of family and unpaid caregivers who assist older adults with health care activities. JAMA Intern Med 2016; 176: 372-379.

4. Davis KL, Marin DB, Kane R, Patrick D, Peskind ER, Raskind MA, Puder KL. The Caregiver Activity Survey (CAS): development and validation of a new measure for caregivers of persons with Alzheimer's disease. Int J Geriatr Psychiatry 1997; 12: 978-988.

5. Darragh AR, Sommerich CM, Lavender SA, Tanner KJ, Vogel K, Campo M. Musculoskeletal discomfort, physical demand, and caregiving activities in informal caregivers. J Appl Gerontol 2015; 34: 734-760.

6. Burns JW, Johnson BJ, Mahoney N, Devine J, Pawl R. Anger management style, hostility and spouse responses: gender differences in predictors of adjustment among chronic pain patients. Pain 1996; 64: 445-453.

7. Flor H, Turk DC, Scholz OB. Impact of chronic pain on the spouse: marital, emotional and physical consequences. J Psychosom Res 1987; 31: 63-71.

8. Kristanti MS, Engels Y, Effendy C, Astuti, Utarini A, Vernooij-Dassen M. Comparison of the lived experiences of family caregivers of patients with dementia and of patients with cancer in Indonesia. Int Psychogeriatr 2018; 30: 903-914.

9. Cross AJ, Garip G, Sheffield D. The psychosocial impact of caregiving in dementia and quality of life: a systematic review and meta-synthesis of qualitative research. Psychol Health 2018; 33:

1321-1342. 
10. LeSeure $\mathrm{P}$, Chongkham-ang $\mathrm{S}$. The experience of caregivers living with cancer patients: a systematic review and meta-synthesis. J Pers Med 2015; 5: 406-439.

11. Ntsayagae El, Poggenpoel M, Myburgh C. Experiences of family caregivers of persons living with mental illness: A meta-synthesis. Curationis 2019; 42: e1-e9.

12. Palacio C, Limonero JT. The relationship between the positive aspects of caring and the personal growth of caregivers of patients with advanced oncological illness: Postraumattic growth and caregiver. Support Care Cancer 2019: In Press.

13. Coloni-Terrapon C, Favrod J, Clément-Perritaz A, Gothuey I, Rexhaj S. Optimism and the psychological recovery process among informal caregivers of inpatients suffering from depressive disorder: a descriptive exploratory study. Front Psychiatr. 2020: In Press.

14. Ribeiro $O$, Brandão D, Oliveira AF, Teixeira L, Paúl C. Positive aspects of care in informal caregivers of community-dwelling dementia patients. J Psychiatr Ment Health Nurs 2019: In Press.

15. Brites R, Brandão T, Moniz Pereira F, Hipólito J, Nunes O. Effects of supporting patients with dementia: A study with dyads. Perspect Psychiatr Care 2020: In Press.

16. Bronfenbrenner U. Friedman SL and Wachs TD (ed). Measuring environment across the life span: Emerging methods and concepts. Washington, DC: American Psychological Association Press, 1999.

17. Elder GH Kirkpatrick Johnson M, Crosnoe R. The Emergence and Development of Life Course Theory. In: Jeylan T. Mortimer and Michael J. Shanahan (ed). Handbook of the Life Course. London: Springer, 2003. Pp. 3-19.

18. Pearlin LI, Mullan JT, Semple SJ, Skaff MM. Caregiving and the stress process: An overview of concepts and their measures. Gerontologist 1990; 30: 583-594.

19. Bowlby J. Attachment. Attachment and loss: Vol. 1. Loss. New York: Basic Books, 1969. 
20. Crosswell AD, Suresh M, Puterman E, Gruenewald T, Lee J, Epel ES. Advancing research on psychological stress and aging with the Health and Retirement Study: Looking back to launch the field forward. J Gerontol B Psychol Sci Soc Sci 2018: In Press.

21. Burns JW, Gerhart JI, Post KM, Smith DA, Porter LS, Schuster E, Buvanendran A, Fras AM, Keefe FJ. The communal coping model of pain catastrophizing in daily life: a within-couples daily diary study. J Pain 2015; 16: 1163-1175.

22. Thorn BE, Ward LC, Sullivan MJL, Boothby JL. Communal coping model of catastrophizing: conceptual model building Pain 2003; 96: 319-324.

23. Monin JK, Zhou L, Kershaw T. Attachment and psychological health in older couples coping with pain._GeroPsych 2014; 27: 115-127.

24. Consedine NS, Magai C. Attachment and emotion experience in later life: the view from emotions theory. Attach Hum Dev 2003; 5: 165-187.

25. Lee J, Sohn BK, Lee H, Seong SJ, Park S, Lee JY. Attachment style and filial obligation in the burden of caregivers of dementia patients. Arch Gerontol Geriatr 2018; 75: 104-111.

26. Blyth FM, Cumming RG, Brnabic AJ, Cousins MJ. Caregiving in the presence of chronic pain.J Gerontol A Biol Sci Med Sci 2008; 63: 399-407.

27. Ciechanowski $P$, Sullivan $M$, Jensen $M$, Romano J, Summers $H$. The relationship of attachment style to depression, catastrophizing and health care utilization in patients with chronic pain. Pain 2003; 104: 627-637.

28. Mohammadi S, Dehghani M, Sanderman R, Hagedoorn M. The role of pain behaviour and family caregiver responses in the link between pain catastrophising and pain intensity: A moderated mediation model._Psychol Health 2017; 32: 422-438.

29. Cano A, Leong LEM, Williams AM, May DKK, Lutz JR. Correlates and consequences of the disclosure of pain-related distress to one's spouse. Pain 2012; 153: 2441-2447. 
30. Issner JB, Cano A, Leonard MT, Williams AM. How do I empathize with you? Let me count the ways: relations between facets of pain-related empathy. J Pain 2012; 13: 167-175.

31. Snelgrove S, Liossi C. Living with chronic low back pain: a meta-synthesis of qualitative research. Chronic IIIn 2013; 9: 283-301.

32. MacNeela P, Doyle C, O'Gorman D, Ruane N, McGuire BE. Experiences of chronic low back pain: a meta-ethnography of qualitative research. Health Psychol Rev 2015; 9: 63-82.

33. Smith TO, Purdy R, Lister S, Salter C, Fleetcroft R, Conaghan P. Living with osteoarthritis: a systematic review and meta-ethnography. Scand J Rheumatol 2014; 43: 441-452.

34. Moher D, Liberati A, Tetzlaff J, Altman DG; PRISMA Group. Preferred reporting items for systematic reviews and meta-analyses: the PRISMA statement. PLoS Med 2009; 6: e1000097.

35. France EF, Cunningham M, Ring N, Uny I, Duncan EAS, Jepson RG, Maxwell M, Roberts RJ, Turley RL, Booth A, Britten N, Flemming K, Gallagher I, Garside R, Hannes K, Lewin S, Noblit GW, Pope C, Thomas J, Vanstone M, Higginbottom GMA, Noyes J. Improving reporting of metaethnography: the eMERGe reporting guidance. BMC Med Res Methodol 2019; $19: 25$.

36. Merskey H, and Bogduk N. Classification of chronic pain. Descriptions of chronic pain syndromes and definitions of pain terms 2nd edition. Seattle, USA: IASP Press, 1994.

37. Noblit GW, Hare RD. Meta-ethnography: synthesizing qualitative studies. California: Newbury Park, 1988.

38. Atkins S, Lewis S, Smith H, Engel M, Fretheim A, Volmink J. Conducting a meta-ethnography of qualitative literature: lesions learnt. BMC Med Res Methodol 2008; 8: 21.

39. Major $\mathrm{CH}$, Savin-Baden $\mathrm{M}$. An introduction to qualitative research synthesis: managing the information explosion in social science research. New York: Routledge, 2010.

40. CASP. Critical Appraisal Skills Programme - Qualitative Research Appraisal Tool. Accessed: 29 Nov 2019. Available at: https://casp-uk.net/casp-tools-checklists/ 
41. McCluskey S, de Vries H, Reneman M, Brooks J, Brouwer S. 'I think positivity breeds positivity': a qualitative exploration of the role of family members in supporting those with chronic musculoskeletal pain to stay at work. BMC Fam Pract 2015; 16: 85.

42. Söderberg S, Strand M, Haapala M, Lundman B. Living with a woman with fibromyalgia from the perspective of the husband. J Adv Nurs 2003; 42: 143-150.

43. McCluskey S, Brooks J, King N, Burton K. The influence of 'significant others' on persistent back pain and work participation: a qualitative exploration of illness perceptions. BMC Musculoskelet Disord 2011; 12: 236.

44. Hsu KY, Tsai YF, Lin YP, Liu HT. Primary family caregivers' observations and perceptions of their older relatives' knee osteoarthritis pain and pain management: a qualitative study. J Adv Nurs 2015; 71: 2119-2128.

45. Richardson JC, Ong BN, Sim J. Experiencing chronic widespread pain in a family context: giving and receiving practical and emotional support. Sociol Health IIIn 2007; 29: 347-365.

46. McCluskey S, Brooks J, King N, Burton K. Are the treatment expectations of 'significant others' psychosocial obstacles to work participation for those with persistent low back pain? Work 2014; 48: 391-398.

47. Sofaer-Bennett B, Walker J, Moore A, Lamberty J, Thorp T, O'Dwyer J. The social consequences for older people of neuropathic pain: a qualitative study. Pain Med 2007; 8: 263-270.

48. Newton-John TR, Williams AC. Chronic pain couples: perceived marital interactions and pain behaviours. Pain 2006; 123: 53-63.

49. West C, Usher K, Foster K, Stewart L. Chronic pain and the family: the experience of the partners of people living with chronic pain. J Clin Nurs 2012; 21: 3352-3360.

50. Sylvain H, Talbot LR. Synergy towards health: a nursing intervention model for women living with fibromyalgia, and their spouses. J Adv Nurs 2002; 38: 264-273. 
51. Mease P. Fibromyalgia syndrome: review of clinical presentation, pathogenesis, outcome measures, and treatment. J Rheumatol Suppl 2005; 75: 6-21.

52. Turk DC, Okifuji A. Psychological factors in chronic pain: evolution and revolution. J Consult Clin Psychol 2002; 70: 678-690.

53. Keefe FJ, Caldwell DS, Baucom D, Salley A, Robinson E, Timmons K, Beaupre P, Weisberg J, Helms M. Spouse-assisted coping skills training in the management of osteoarthritic knee pain. Arthritis Care Res 1996; 9: 279-291.

54. Keefe FJ, Caldwell DS, Baucom D, Salley A, Robinson E, Timmons K, Beaupre P, Weisberg J, Helms M. Spouse-assisted coping skills training in the management of knee pain in osteoarthritis: long-term followup results. Arthritis Care Res 1999; 12: 101-111.

55. Keefe FJ, Blumenthal J, Baucom D, Affleck G, Waugh R, Caldwell DS, Beaupre P, KashikarZuck S, Wright K, Egert J, Lefebvre J. Effects of spouse-assisted coping skills training and exercise training in patients with osteoarthritic knee pain: a randomized controlled study. Pain 2004; 110 : 539-549.

56. Clauw DJ, D'Arcy Y, Gebke K, Semel D, Pauer L, Jones KD. Normalizing fibromyalgia as a chronic illness. Postgrad Med 2018; 130: 9-18.

57. Atkins D, Uskul AK, Cooper NR. Culture shapes empathic responses to physical and social pain. Emotion 2016; 16: 587-601.

58. Fernández-Ballesteros R, Bustillos A, Santacreu M, Schettini R, Díaz-Veiga P, Huici C. Is older adult care mediated by caregivers' cultural stereotypes? The role of competence and warmth attribution. Clin Interv Aging 2016; 11: 545-552.

59. Revenson TA, Griva K, Luszczynska A, Morrison V, Panagopoulou E, Vilcghinsky N, Hagedoorn M. Caregiving in the Illness Context. Basingstoke: Palgrave Macmillan, 2016. 
Figure 1: PRISMA flow-chart illustrating the search strategy results.
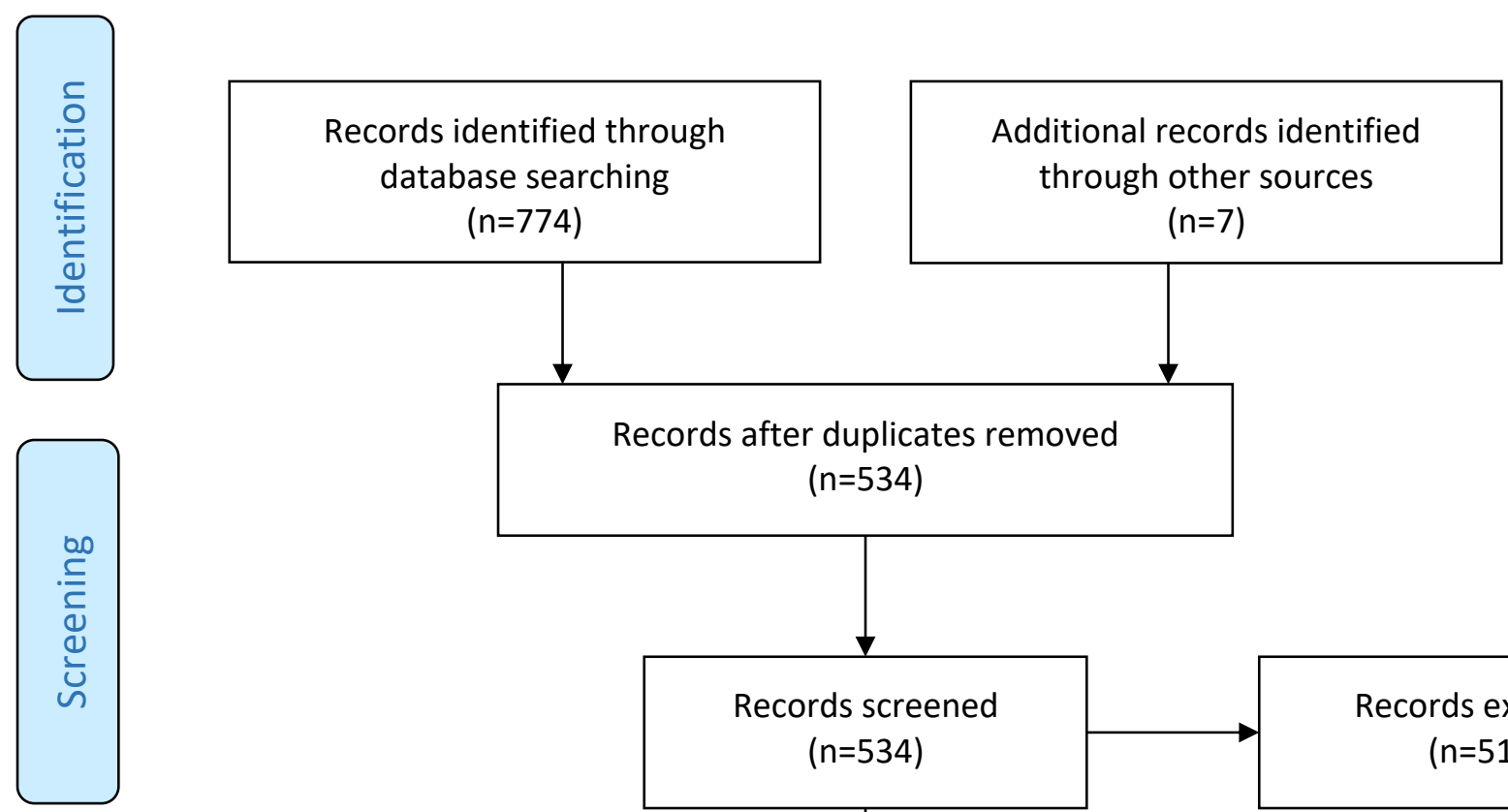

Records after duplicates removed $(n=534)$
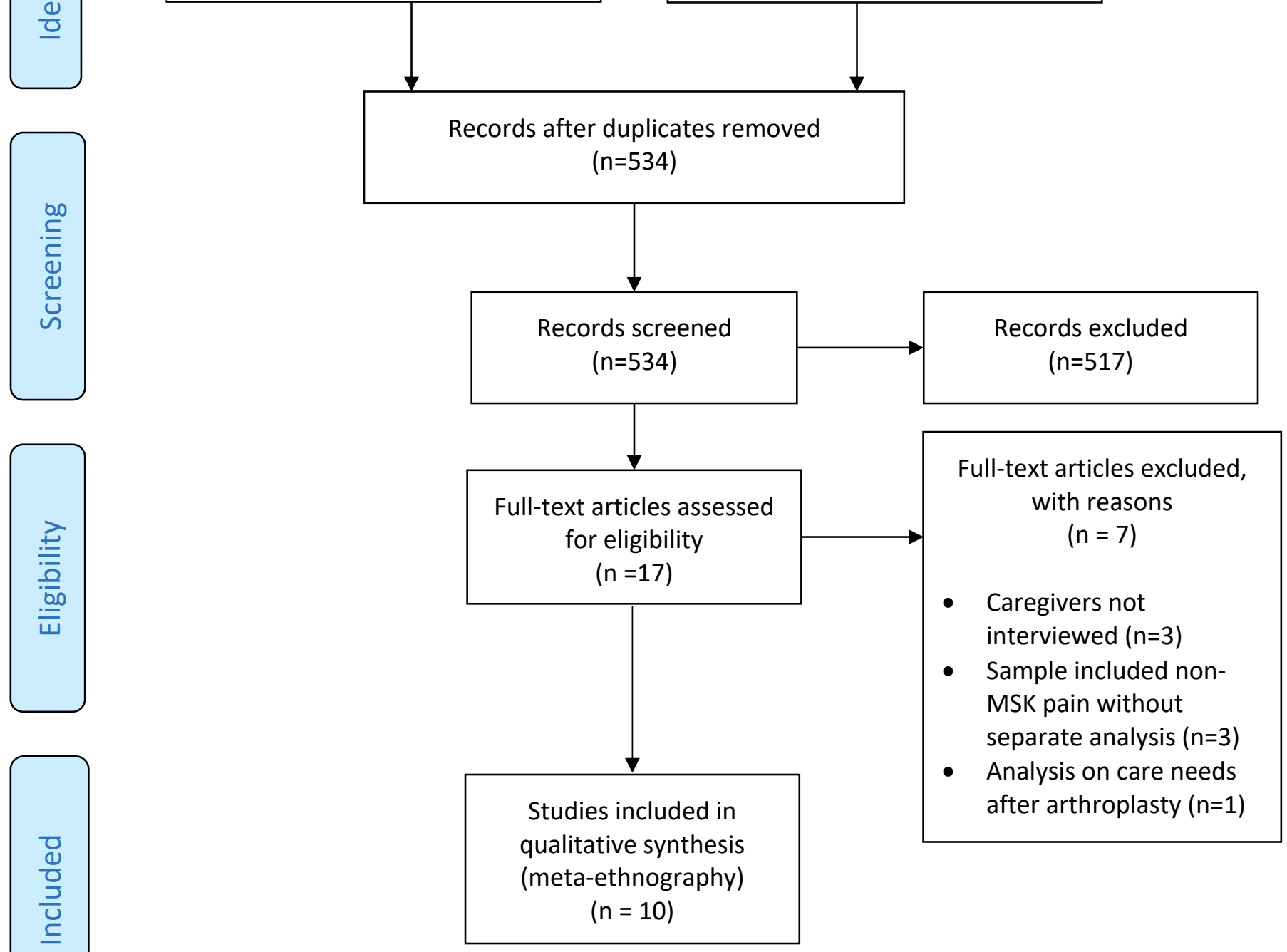

(meta-ethnography)

$(n=10)$ 
Table 1: A summary of the characteristics of the ten included studies in this systematic review.

\begin{tabular}{|c|c|c|c|c|c|c|c|c|c|}
\hline \multirow{2}{*}{$\begin{array}{l}\text { Study \& } \\
\text { Published } \\
\text { Year }\end{array}$} & \multirow[t]{2}{*}{ Origin } & \multirow{2}{*}{$\begin{array}{l}\text { N (Care } \\
\text { Recipient \& } \\
\text { Caregiver) }\end{array}$} & \multicolumn{2}{|c|}{ Care Recipient } & \multicolumn{2}{|c|}{ Caregiver } & \multirow[b]{2}{*}{$\begin{array}{l}\text { Caregiver Relationship } \\
\text { to Care Recipient }\end{array}$} & \multirow[t]{2}{*}{ Musculoskeletal Disorder } & \multirow{2}{*}{$\begin{array}{l}\text { Duration } \\
\text { Symptoms } \\
\text { (months) }\end{array}$} \\
\hline & & & $\begin{array}{l}\text { Gender } \\
\text { (M/F) }\end{array}$ & $\begin{array}{l}\text { Mean Age } \\
\text { (Yrs) }\end{array}$ & $\begin{array}{l}\text { Gender } \\
\text { (M/F) }\end{array}$ & $\begin{array}{l}\text { Mean Age } \\
\text { (Yrs) }\end{array}$ & & & \\
\hline $\begin{array}{l}\text { Hsu et al } \\
{[44] 2015}\end{array}$ & Taiwan & CG: 28 & $4 / 24$ & 74.2 & $15 / 13$ & 48.0 & $\begin{array}{l}\text { Son: } 50 \% \\
\text { Daughter-in-law: } 25 \% \\
\text { Daughter: } 17.5 \% \\
\text { Husband: } 3.6 \% \\
\text { Granddaughter: } 3.6 \%\end{array}$ & Knee Osteoarthritis & $\begin{array}{l}91.3 \\
\text { (SD: } 87.4)\end{array}$ \\
\hline $\begin{array}{l}\text { McCluskey } \\
\text { et al [43] } \\
2011\end{array}$ & UK & $\begin{array}{l}\text { CG: } 5 \\
\text { CR: } 5\end{array}$ & $4 / 1$ & 41 & $0 / 5$ & 40.2 & $\begin{array}{l}\text { Spouse: } 3 \\
\text { Child: } 2\end{array}$ & $\begin{array}{l}\text { Chronic pain with patient on } \\
\text { incapacity benefit }\end{array}$ & $N / D$ \\
\hline $\begin{array}{l}\text { McCluskey } \\
\text { at al [46] } \\
2014\end{array}$ & UK & $\begin{array}{l}\text { CG: } 9 \\
\text { CR: } 9\end{array}$ & $\mathrm{~N} / \mathrm{D}$ & 48.1 & $N / D$ & 49.7 & $\begin{array}{l}\text { Spouse: } 7 \\
\text { Child: } 2\end{array}$ & $\begin{array}{l}\text { MSK Pain with patient on } \\
\text { incapacity benefit }\end{array}$ & $\mathrm{N} / \mathrm{D}$ \\
\hline $\begin{array}{l}\text { McCluskey } \\
\text { et al [41] } \\
2015\end{array}$ & $\begin{array}{l}\text { UK and } \\
\text { Netherlands }\end{array}$ & $\begin{array}{l}\text { CR: } 31 \\
\text { CG: } 31\end{array}$ & $5 / 4$ & $\begin{array}{l}\text { UK } \\
49.2 \\
\text { Netherlands } \\
49.0\end{array}$ & $3 / 6$ & $\begin{array}{l}\text { UK: } 36.6 \\
\text { Netherlands: } \\
50.2\end{array}$ & $N / D$ & $\begin{array}{l}\text { UK: } 100 \% \text { LBP and on } \\
\text { incapacity benefit } \\
\text { Netherlands: } 50 \% \text { LBP. } \\
\text { N/D 50\% }\end{array}$ & $N / D$ \\
\hline $\begin{array}{l}\text { Newton- } \\
\text { John and } \\
\text { Williams } \\
\text { [48] } 2006\end{array}$ & UK & $\begin{array}{l}\text { CR: } 80 \\
\text { CG: } 80\end{array}$ & $38 / 57$ & 48.2 & $57 / 38$ & 49.1 & Spouses: $100 \%$ & Chronic pain & $\begin{array}{l}9.7 \\
\text { (SD: 9.2) }\end{array}$ \\
\hline $\begin{array}{l}\text { Richardson } \\
\text { et al [45] } \\
2007\end{array}$ & UK & $\begin{array}{l}\text { CR: } 8 \\
\text { CG: } 5\end{array}$ & $4 / 4$ & 51.8 & $N / D$ & N/D & $\begin{array}{l}\text { Spouse: } 4 \\
\text { Daughter: } 1\end{array}$ & Chronic widespread pain & $>3$ months \\
\hline $\begin{array}{l}\text { Söderberg } \\
\text { et al [42] } \\
2003\end{array}$ & Sweden & $\begin{array}{l}\text { CR: } 5 \\
\text { CG: } 5\end{array}$ & $0 / 5$ & $N / D$ & $5 / 0$ & 55 & Spouses: $100 \%$ & Fibromyalgia & $\mathrm{N} / \mathrm{D}$ \\
\hline $\begin{array}{l}\text { Sofaer- } \\
\text { Bennett et } \\
\text { al [47] } 2007\end{array}$ & UK & $\begin{array}{l}\text { CR: } 16 \\
\text { CG: } 9\end{array}$ & $6 / 10$ & $60-84$ & $\mathrm{~N} / \mathrm{D}$ & $\mathrm{N} / \mathrm{D}$ & Spouse or partner & Neuropathic pain & $>3$ months \\
\hline $\begin{array}{l}\text { Sylvain et al } \\
\text { [50] } 2002\end{array}$ & Canada & $\begin{array}{l}\text { CR: } 7 \\
\text { CR: } 4\end{array}$ & $0 / 7$ & 50 & $4 / 0$ & 53 & Spouse: $100 \%$ & Fibromyalgia & $\begin{array}{l}12 \text { years } \\
(4-20)\end{array}$ \\
\hline
\end{tabular}




\begin{tabular}{l|l|l|l|l|l|l|l|l|l}
\hline $\begin{array}{l}\text { West et al } \\
{[49] 2012}\end{array}$ & Australia & CG: 9 & N/D & N/D & $4 / 5$ & $29-60$ & $\begin{array}{l}\text { Partners/family } \\
\text { members: } 9\end{array}$ & Chronic pain & 4-30 years \\
\hline
\end{tabular}

CG - Caregiver; CR - Care Recipient; F - Female; LBP - Low Back Pain; M - Male; N/D - Not Documents; SD - standard deviation; UK - United Kingdom; Yrs - Years 
Table 2: A summary of the CASP critical appraisal results for the ten included studies in this systematic review.

\begin{tabular}{l|c|c|c|c|c|c|c|c|c|c}
\hline \multirow{2}{*}{ Study } & \multicolumn{10}{c}{ CASP Qualitative Criterion } \\
\cline { 2 - 11 } & $\mathbf{1}$ & $\mathbf{2}$ & $\mathbf{3}$ & $\mathbf{4}$ & $\mathbf{5}$ & $\mathbf{6}$ & $\mathbf{7}$ & $\mathbf{8}$ & $\mathbf{9}$ & $\mathbf{1 0}$ \\
\hline Hsu et al [44] & $\mathrm{Y}$ & $\mathrm{Y}$ & $\mathrm{Y}$ & $\mathrm{Y}$ & $\mathrm{Y}$ & $\mathbf{N}$ & $\mathrm{Y}$ & $\mathrm{Y}$ & $\mathrm{Y}$ & $\mathrm{Y}$ \\
\hline McCluskey et al [43] & $\mathrm{Y}$ & $\mathrm{Y}$ & $\mathrm{Y}$ & $\mathrm{Y}$ & $\mathrm{Y}$ & $\mathrm{N}$ & $\mathrm{Y}$ & $\mathrm{Y}$ & $\mathrm{Y}$ & $\mathrm{Y}$ \\
\hline McCluskey et al [46] & $\mathrm{Y}$ & $\mathrm{Y}$ & $\mathrm{Y}$ & $\mathrm{Y}$ & $\mathrm{Y}$ & $\mathrm{N}$ & $\mathrm{Y}$ & $\mathrm{Y}$ & $\mathrm{Y}$ & $\mathrm{Y}$ \\
\hline McCluskey et al [41] & $\mathrm{Y}$ & $\mathrm{Y}$ & $\mathrm{Y}$ & $\mathrm{Y}$ & $\mathrm{Y}$ & $\mathrm{N}$ & $\mathrm{Y}$ & $\mathrm{Y}$ & $\mathrm{Y}$ & $\mathrm{Y}$ \\
\hline Newton-John and Williams [48] & $\mathrm{Y}$ & $\mathrm{Y}$ & $\mathrm{Y}$ & $\mathrm{Y}$ & $\mathrm{Y}$ & $\mathrm{N}$ & $\mathrm{Y}$ & $\mathrm{Y}$ & $\mathrm{Y}$ & $\mathrm{Y}$ \\
\hline Richardson et al [45] & $\mathrm{Y}$ & $\mathrm{Y}$ & $\mathrm{Y}$ & $\mathrm{Y}$ & $\mathrm{Y}$ & $\mathrm{N}$ & $\mathrm{Y}$ & $\mathrm{Y}$ & $\mathrm{Y}$ & $\mathrm{Y}$ \\
\hline Söderberg et al [42] & $\mathrm{Y}$ & $\mathrm{Y}$ & $\mathrm{Y}$ & $\mathrm{Y}$ & $\mathrm{Y}$ & $\mathrm{N}$ & $\mathrm{Y}$ & $\mathrm{Y}$ & $\mathrm{Y}$ & $\mathrm{Y}$ \\
\hline Sofaer-Bennett et al [47] & $\mathrm{Y}$ & $\mathrm{Y}$ & $\mathrm{Y}$ & $\mathrm{Y}$ & $\mathrm{Y}$ & $\mathrm{N}$ & $\mathrm{Y}$ & $\mathrm{Y}$ & $\mathrm{Y}$ & $\mathrm{Y}$ \\
\hline Sylvain et al [50] & $\mathrm{Y}$ & $\mathrm{Y}$ & $\mathrm{Y}$ & $\mathrm{Y}$ & $\mathrm{Y}$ & $\mathrm{N}$ & $\mathrm{Y}$ & $\mathrm{Y}$ & $\mathrm{Y}$ & $\mathrm{Y}$ \\
\hline West et al [49] & $\mathrm{Y}$ & $\mathrm{Y}$ & $\mathrm{Y}$ & $\mathrm{Y}$ & $\mathrm{Y}$ & $\mathrm{N}$ & $\mathrm{Y}$ & $\mathrm{Y}$ & $\mathrm{Y}$ & $\mathrm{Y}$ \\
\hline
\end{tabular}

$\mathrm{Y}=$ Satisfied; $\mathrm{N}=$ Not satisfied

CASP Critical Appraisal Criteria: 1 Was there a clear statement of the aims of the research?; 2 Is a qualitative methodology appropriate?; 3 Was the research design appropriate to address the aims of the research?; 4 Was the recruitment strategy appropriate to the aims of the research?; 5 Were the data collected in a way that addressed the research issue?; 6 Has the relationship between researcher and participants been adequately considered?; 7 Have ethical issues been taken into consideration?; 8 Was the data analysis sufficiently rigorous?; 9 Is there a clear statement of findings?; 10 is the research valuable to clinical practice? 
Table 3: Matrix of first-, second- and third-order constructs and their attribution to included study.

\begin{tabular}{|c|c|c|}
\hline First-Order Constructs & Second-Order Constructs & Third-Order Constructs \\
\hline \multirow[t]{3}{*}{$\begin{array}{l}\text { Peripheral care not central care for the healthcare } \\
\text { professional - key 'alley' not 'central' player }[41,43,45,50]\end{array}$} & $\begin{array}{l}\text { Separate yet parallel caregiving/support to healthcare professionals } \\
\text { - synergy model [50] }\end{array}$ & \multirow[t]{7}{*}{$\begin{array}{l}\text { Caregiving dyad-healthcare } \\
\text { professional relationship }\end{array}$} \\
\hline & Need to be empowered to "speak out from the system" [50] & \\
\hline & $\begin{array}{l}\text { Healthcare professional is the authoritarian position to control the } \\
\text { healthcare provision for the care-recipient - caregivers have a lesser } \\
\text { role to overall management [41] }\end{array}$ & \\
\hline $\begin{array}{l}\text { Caregiving role is to mediate between health professional and } \\
\text { care-recipient to 'stand up' for caregiver and encouragement } \\
\text { to access care }[42,44]\end{array}$ & $\begin{array}{l}\text { Encouragement for accessing care particularly evident for older } \\
\text { people, potentially due to their personal attitudes to ageing and } \\
\text { degenerative musculoskeletal conditions [44] }\end{array}$ & \\
\hline $\begin{array}{l}\text { Frustration and anger that no cure and being powerless to } \\
\text { health professionals }[46,47]\end{array}$ & \multirow[t]{3}{*}{$\begin{array}{l}\text { Physical assistance 'key' component to caregiving which shouldn't } \\
\text { be underestimated [44] }\end{array}$} & \\
\hline $\begin{array}{l}\text { Failure by health care professionals through medication and } \\
\text { physiotherapy to 'fix' the problem, offering poor perception } \\
\text { of health services [46] }\end{array}$ & & \\
\hline $\begin{array}{l}\text { Seen as the 'helping hand' compared to health professionals } \\
\text { [44] }\end{array}$ & & \\
\hline Changing role of caregiver from care-recipient $[42,45]$ & \multirow{2}{*}{$\begin{array}{l}\text { In a backdrop of poorer identity lost in being a caregiver, caregivers } \\
\text { act to try to normalise the situation and control as an outward site } \\
\text { to society from a social/occupational position once had [45] }\end{array}$} & \multirow[t]{2}{*}{ Role Reversal } \\
\hline Poor perceived identity in changing role [45] & & \\
\hline $\begin{array}{l}\text { Constant presence with care-recipient everyday so knows } \\
\text { what they are going through }[42,45]\end{array}$ & \multirow[t]{3}{*}{ Burden of the isolating position of caregiving [49] } & \multirow[t]{3}{*}{$\begin{array}{l}\text { Constant burden of } \\
\text { Caregiving }\end{array}$} \\
\hline $\begin{array}{l}\text { Self-blame where caregiver feels powerless but then also } \\
\text { resents the situation and feels guilty for feeling this [49] }\end{array}$ & & \\
\hline $\begin{array}{l}\text { Restarting work as a result of financial constraints. Placing } \\
\text { burden and sacrifice on previous lifestyles [42] }\end{array}$ & & \\
\hline $\begin{array}{l}\text { Invisibility of pain makes 'showing it externally' challenging } \\
\text { with negative perception of this }[43,45]\end{array}$ & & Legitimising the condition \\
\hline
\end{tabular}


Caregiver acting as the 'guarantor' to symptoms against a doubting society $[42,43]$

Maintain identity and control over past life [45]
The invisibility of pain makes challenging of cultural stereotypes of low back pain 'malingers' difficult and creates stress for the

caregivers to 'defend' their care-recipients [43]

Reciprocal Supportive Relationship where husband-wife caregiving dyads are 'supportive partnerships' making strong caregiving dyads [45]

Caregiver is the 'information controller' to create the image of

a 'normal life' to friend and family [45]

Partnership activities are beneficial to both caregiver and care-recipient, particularly physically active ones for family bonding [41]

Loss of financial security and family and friend networks as care-recipient unable to meet social goals which impact on lifestyle of caregiver - creates stress, uncertainty and resentment $[42,47,49]$

Impact on sexual and love life where the dyad is in a sexual relationship - creates resentment (West 2012) and difficulty in sleeping in general creates challenges - move to a second bedroom [47]

Love for the care-recipient means caregiving is a pleasure/gift [50]

Perception poor of disease in society so legitimises verbally Strengthening bond with care
level of relationship $[42,50]$ reduced due to physical restriction of care-recipient or having to care for the care-recipient in-doors [47]

Loss of one lifestyle to gain another not out of choice but necessity [42]

The 'shrinking exterior world' [49]

Change from a lover role to a nursing role creates resentment of the situation [49]- marital strain

Strengthening bond with caregiving offering opportunity to another $[42,45]$

Only person who they can talk to $[44,45]$

Emotional support equally as important than physical support $[42,45]$

Caregivers present with different caregiving approaches

including: active participant, observer, shielding behaviours or

challenging pain behaviours [48]
Family and societal

perceptions 
Only real-life assessment can convey the symptoms due to fluctuating pain symptoms $[42,45,47]$

Helping hand but not sufficiently skilled $[45,50]$

Under-skilled but desire to be in greater control of their situation with caregiving skills are seen as one way to do $[44,50]$

First-order construct: the primary themes generated from participant's responses from the included studies; second-order construct: the interpretations of participants' responses made by authors of included studies; third-order construct: the interpretation of first- and second-order constructs by the systematic reviewers
The uncertainties (fluctuation, fear of it and consequences of it on falling) impose by potential for pain are almost as restrictive as the pain itself [47]

Ecological Systems Theory suggested where the interpretation of

Knowledge and Skills may raise care [50] 
Supplementary Table 1: The MEDLINE search strategy adopted in this systematic review.

1. $\exp$ PAIN/

2. $\exp$ ARTHRITIS, RHEUMATOID/

3. $\exp$ FIBROMYALGIA/

4. $\exp$ OSTEOARTHRITIS/

5. MUSCULOSKELETAL DISEASES/

6. $\exp$ ARTHRITIS/

7. $\mathrm{OR} / 1-6$

8. cancer.ti,ab

9. 7 NOT 8

10. exp.caregiver/

11. ("informal caregiver" OR spouse or partner or couples OR couple OR "married person" OR "married persons" OR husband OR husbands OR "domestic partner" OR "domestic partners" OR "spousal notification" OR wife OR wives OR "family caregivers" OR "spouse caregiver" OR "spouse caregivers" OR "intimate partner" OR "home care" OR "significant other" OR "close person" OR friend/ OR relative/ OR exp parent/ OR family/OR extended family/OR exp family relation/OR exp nuclear family/OR volunteer/OR voluntary worker/ OR family centered care/ OR family health/ OR family interaction/ OR family therapy/ OR family life/).tw.

12. (carer* OR caregiver* OR care giver* OR care-giver*).ti,ab

13. next of kin.ti,ab

14. ((non-professional OR non professional OR informal OR volunteer* OR relative or relatives) adj5 (exercise* OR rehabilitat* OR therap* OR train*)).ti,ab

15. OR/10-14

16. RESEARCH, QUALITATIVE/

17. ATTITUDE TO HEALTH/

18. INTERVIEWS AS TOPIC/

19. FOCUS GROUPS/

20. LIFE EXPERIENCES/

21. (qualitative OR ethno\$OR emic OR etic OR phenomenolog).ti,ab

22. (focus AND group $\$ O R$ grounded AND theory OR narrative AND analysis OR lived AND experience $\$ O R$ life).ti, ab

23. (theoretical AND sampl\$OR purposive AND sampl\$OR ricoeur OR spiegelberg\$OR merleau).ti,ab

24. (field AND note\$OR field AND record\$OR fieldnote\$OR field AND stud\$).ti,ab

25. (participant\$adj3 observ\$).ti, ab

26. (unstructured AND categor $\$ O R$ structured AND categor\$).ti,ab

27. OR/16-26

28. AND/9,15,26 
